\title{
Molecular Assessment of DNA Methylation Biomarkers in Egyptian Hepatocellular carcinoma Patients
}

Dalia M. Abd El-Hassib ${ }^{a}$, Azza A. Abo senna ${ }^{a}$, Ebada M. Said ${ }^{b}$, Wafaa M. Abdallah ${ }^{\text {a }}$, Nermien H. Ibrahiem ${ }^{\text {a }}$, Seham Gouda ${ }^{\mathrm{a}}$

a Department of Clinical and Chemical Pathology Department, Faculty of Medicine, Benha University, Benha, Egypt. b Department of Hepatology, Gastroenterology and Infectious Diseases Department, Faculty of Medicine, Benha University, Benha, Egypt.

Correspondence to: Seham Gouda, Department of Clinical and Chemical Pathology Department, Faculty of Medicine, Benha University, Benha, Egypt.

Email:

seham.ameen@fmed.bu.edu.eg

Received: 10 March 2021

Accepted: 8 September 2021

\section{Abstract}

BACKGROUND: HCC is a primary tumor of the liver. It is one of the most common malignancies in adults. OBJECTIVE: Assessment of DNA methylation of BMP4, TSPYL5, APC1 and p16 genes in Egyptian hepatocellular carcinoma patients. METHODS: The present study included 180 subjects classified into: group (I) 60 HCC patients, group (II) 60 chronic liver disease patients with chronic $\mathrm{HCV}$ infection who were diagnosed by presence of $\mathrm{HCV}$ Abs for more than 6 months and quantitative PCR for HCV RNA and group (III) 60 apparently healthy volunteers as control subjects. For all participants, the following was done: Routine lab investigation including CBC, PT, PC, AST, ALT, ALP, albumin, Bilirubin, creatinine, AFP, abdominal ultrasonography, Spiral triphasic CT, and molecular assessment of p 16, TSPYL5, ACP1, BMP4 methylation status. RESULTS: Gene expression by RT-PCR technique among studied groups; APC1, BMP4, TSPYL5, and P16 were statistically significant $(\mathrm{p}<0.001)$ in HCC compared to control. CONCLUSIONS: Hypermethylation of p16, ACP1, BMP4, and TSPYL 5 are common events in patients with HCC and could be used as potentially detectable biomarkers in HCC...

Keywords: DNA methylation, DNA biomarkers, Hepatocellular carcinoma, chronic liver disease, HCV.

\section{Introduction}

Hepatocellular carcinoma (HCC) is a common disorder worldwide and ranks second and six the most common cancer among men and women in Egypt respectively (1).
$\mathrm{HCC}$ is a primary tumor of the liver. It is one of the most common malignancies in adults, and is more common in men than women (2-4:1). Worldwide, over a million deaths per year (about $10 \%$ of all deaths in 
the adult age range) can be attributed to HCC. The occurrence of HCC varies widely depending on geographic location. Many experts expect incident cerates to decline in the Far East due to universal immunization for hepatitis B (2).

Investigations in Egypt have shown the increasing importance of $\mathrm{HCV}$ infection in the etiology of liver cancer, estimated to account for $40-50 \%$ of cases, and the declining influence of $\mathrm{HBV}$ and $\mathrm{HBV} /$ HCV infection (25\& 15\%, respectively) (3).

Ultrasonography is the most widely used in imaging test for screening because of its diagnostic accuracy, non-invasiveness, good acceptance by patients, and moderate cost (4).

Among serological biomarkers, alphafetoprotein (AFP) is the most extended serum marker for HCC screening, it is routinely used by clinicians although its insufficient sensitivity and specificity (4).

In human genome, Deoxy nucleic acid (DNA) methylation occurs almost exclusively at $\mathrm{CpG}$ di nucleotide ecytosine residue of a $\mathrm{CpG}$ di nucleotide can be covalently modified by adding a methyl group to its 5-carbon atom resulting in 5methyl cytosine transferred from $\mathrm{S}$ adenosyl -L-methionine to a cytosine residue via DNA methyl transferases $\mathrm{CpGn}$ (5).

The mechanisms of liver cancer induction are now known to include mutations in specific genes and epigenetic alterations such as changes in DNA methylation and micro RNA expression. These changes lead to changes in expression of oncogenes and tumor suppressor genes. DNA hyper methylation can silence tumor suppressor genes while hypo- methylation can activate oncogenes (6).

Many studies concentrate on characterizing the clinical relevance for the methylation of bone morphogenetic protein 4 (BMP4) and testis - specific protein Y-encoded like 5 (TSPYL5) and their clinical application into large cohort of HCC patients and evaluating their potential clinical significance (7).

The present study tried to evaluate DNA methylation of APC1, BMP 4, TSPYL 5 and p16 genes in Egyptian HCC patients.

\section{Material and methods}

The present study is a case control study, it is an immuno-assay trail that was performed on HCC patients who were attended to the Hepatology and Gastroenterology department and work-up was performed at the Clinical Pathology Department, Benha University.

Approval of the study protocol by the ethical scientific committee of Benha faculty of Medicine, Benha University. Informed medical consent was obtained from all patients before enrollment in the 
study. The study included 180 subjects divided as the following : HCC group (I) includes $60 \mathrm{HCC}$, post $\mathrm{HCV}$ infection diagnosed by 2 radiological methods with or without AFP > $200 \mathrm{ng} / \mathrm{ml}$, they were 29 males and 31 females with mean age 52.91 \pm 7.27 years.CLD group (II) included 60 CLD patients with chronic HCV, diagnosed by presence of $\mathrm{HCV}$ antibodies for more than 6 months and quantitative PCR for HCV RNA, they were 30 males and 30 females with mean age $49.89 \pm 9.7$ years. Control group (III) included 60 apparently healthy volunteers; 28 males and 32 females with mean age $48.1 \pm 11.4$ years, they were age and sex matched with the patient groups.

\section{Exclusion criteria:}

Age $<18$ years, Pregnant females, Hepatitis other than HCV (HBsAg +ve \& so on), Patients received any type of cancer therapy, other malignancies than HCC. Patients with mixed infection, Schistosomal, or Alcohol intake.

\section{Technical Design:}

All patients included in the study were subjected to the following: Thorough history and complete clinical examination and radiological investigations by:

\section{Abdominal ultrasonography:}

Real time abdominal U/S was done by -GE health care LOGIQE 9 machinell.

\section{Spiral triphasic CT:}

It was performed for patients with $\mathrm{HCC}$ for confirmation of U/S findings and evaluation of focal lesion.

\section{Laboratory investigations:}

Routine blood tests: CBC, PT, CT, liver and kidney function tests.

\section{- Special investigations:}

1. Serum HBs antigen by enzyme linked immune sorbent assay (ELISA) and HCV anti bodies by $3^{\text {rd }}$ generation ELISA kit supplied by Siemens Diagnostics.

2. Serum alpha-feto protein (AFP) was assayed in serum samples by solid phase, two-site sequential chemilumines centimmuno metric assay by automated analyzer Immulite 2000 using kit supplied by Siemens Diagnostics ,Los Angeles, USA.

3. Determination of p16, TSPYL 5, ACP1, BMP4 methylation status by the following steps:

a.Extraction of genomic DNA from EDTA anti coagulated whole blood.

b.Bisulfite modification of extracted DNA.

c. Amplification of the modified DNA.

d.Detection of PCR amplification products using Tag polymerase enzyme and Hybaid thermal cycler (Promega Corporation, USA). 


\section{Gene sequence:}

- P16: TTA TTA GAG GGT GGG GCG GAT CGC (sense).

- GAC CCC GAA CCG CGA CCG TAA (anti sense).

- TSPYl5: AGA AAA TAG GTG ATG GGG GA (sense)

- APC1: CGG GTA TTT ATT GTT GTTC (sense)

- ACC TTA AAC CTA AAC GCTC (anti sense)

- BMP4: CGG GAG GAG GAA GGA GAG (sense)

- CCG CAA ATC GAC GAA AATA (anti sense)

\section{Statistical data analysis:}

Data were coded and entered the statistical

\section{Results}

package SPSS version22 (SPSS Armonk,

This study contains 3 equal groups of 60 NY: IBM Corp). Data were statistically described in terms of mean, standard deviation, for quantitative data and frequencies (number of cases) and relative frequencies (percentages) for qualitative data. For comparing categorical data, Chisquare (c2) test was performed. ANOVA was used to compare quantitative variables between the three groups. Receiver operator characteristic (ROC) curves were derived and area - under -the curve (AUC) analysis performed to get the best cut off values for detecting $\mathrm{HCC}$ cases. A probability value ( $\mathrm{P}$ value) less than 0.05 was considered statistically significant. Correlations between quantitative variables were done using Pearson correlation coefficient. subjects each, they were matched in age and sex as the mean age \pm SD was $48.1 \pm$ $11.4,49.89 \pm 9.7$ and $52.91 \pm 7.27$ years in control, CLD, and HCC patients, respectively $(\mathrm{P}>0.05)$. The male/female ratios were statistically insignificant ( $\mathrm{P}>0.05$ between the three studied groups. Also, comparison between the three studied groups as regard INR, Albumin and hemoglobin concentration were insignificant, while AST, ALT, S. Bilirubin, AFP and platelets were statistically significant $(\mathrm{P}<0.05)$ as shown in table (1).

Gene expression by RT-PCR technique among studied groups; the mean APC1, BMP4, TSPYL5 and p16 levels between the three groups showed a statistically significant difference (table 2). The 
diagnostic accuracy of the different studied markers for HCC was $92 \%, 97 \%, 88.5 \%$ \& $95 \%$ in the 4 studied biomarkers respectively (table 3). However, the diagnostic accuracy of the different studied markers for CLD was lower than $\mathrm{HCC}$, it was $57 \%, 42 \%, 73.5 \% \& 58 \%$ in the 4 studied biomarkers respectively (table 4). This was illustrated in the ROC curves for the 4 studied biomarkers (Fig. 1, 2).

Table (1): Demographic data among the studied groups

\begin{tabular}{|c|c|c|c|c|c|}
\hline & $\begin{array}{c}\text { Control } \\
(n=60)\end{array}$ & $\begin{array}{c}\text { CLD } \\
(n=60)\end{array}$ & HCC $(n=60)$ & $\begin{array}{c}\mathbf{P 1} \\
\text { value }\end{array}$ & $\begin{array}{c}\text { P2 } \\
\text { value }\end{array}$ \\
\hline Age (years) & $48.1 \pm 11.4$ & $49.89 \pm 9.7$ & $52.91 \pm 7.27$ & $\begin{array}{l}0.8 \\
0.6\end{array}$ & 0.5 \\
\hline $\begin{array}{l}\text { Females: } \mathbf{n}(\%) \\
\text { Males: } \mathbf{n}(\%)\end{array}$ & $\begin{array}{l}32(44 \%) \\
28(56 \%)\end{array}$ & $\begin{array}{l}30(44 \%) \\
30(56 \%)\end{array}$ & $\begin{array}{l}31(44 \%) \\
29(56 \%)\end{array}$ & $\begin{array}{c}0.7 \\
0.85\end{array}$ & 0.6 \\
\hline T-Bilirubin (mg/dl) & $0.84 \pm 0.11$ & $2.13 \pm 1.28$ & $4.48 \pm 0.46$ & $\begin{array}{c}0.02 \\
<0.001\end{array}$ & 0.001 \\
\hline INR & $1 \pm 0.00$ & $1.24 \pm 0.28$ & $1.3 \pm 0.12$ & $\begin{array}{c}0.06 \\
0.012\end{array}$ & 0.7 \\
\hline $\operatorname{AST}(\mathbf{U} / \mathbf{L})$ & $20.8 \pm 3.7$ & $55 \pm 13.7$ & $65.5 \pm 6.4$ & $\begin{array}{l}<0.001 \\
<0.001\end{array}$ & 0.027 \\
\hline $\operatorname{ALT}(\mathbf{U} / \mathbf{L})$ & $24.6 \pm 5.6$ & $62.4 \pm 16.3$ & $85.3 \pm 4.8$ & $\begin{array}{l}<0.001 \\
<0.001\end{array}$ & $<0.001$ \\
\hline Albumin (g/dl) & $4.2 \pm 0.3$ & $3.5 \pm 1.6$ & $2.3 \pm 1.29$ & $\begin{array}{r}0.6 \\
0.02\end{array}$ & 0.09 \\
\hline$\underline{\alpha}$ fetoprotein & $0.93 \pm 0.30$ & $0.95 \pm 0.29$ & $1.87 \pm 0.17$ & $\begin{array}{c}1 \\
<0.001\end{array}$ & $<0.001$ \\
\hline Hb (\%) & $14.6 \pm 0.9$ & $9.8 \pm 1.7$ & $8.6 \pm 1.25$ & $\begin{array}{l}<0.001 \\
<0.001\end{array}$ & 0.09 \\
\hline Platelet $\times 10^{3}$ & $204 \pm 38.9$ & $120 \pm 49$ & $86 \pm 21$ & $\begin{array}{l}<0.001 \\
<0.001\end{array}$ & 0.004 \\
\hline
\end{tabular}

$\mathrm{p}<0.05$ : significant.

Table (2): Gene expression by RT-PCR technique among studied groups

\begin{tabular}{|c|c|c|c|c|c|}
\hline & Normal $(n=60)$ & $\operatorname{CLD}(n=60)$ & $\mathrm{HCC}(n=60)$ & P1 value & P2 value \\
\hline APC1 & $1.48 \pm 0.75$ & $2 \pm 0.77$ & $2.7 \pm 0.23$ & $\begin{array}{c}0.07 \\
<0.001\end{array}$ & 0.01 \\
\hline BMP4 & $1.5 \pm 0.64$ & $1.65 \pm 0.93$ & $3.5 \pm 1.1$ & $\begin{array}{c}0.89 \\
<0.001\end{array}$ & $<0.001$ \\
\hline TSPYL5 & $1.8 \pm 0.97$ & $3.8 \pm 0.63$ & $5.6 \pm 2$ & $\begin{array}{l}<0.001 \\
<0.001\end{array}$ & 0.003 \\
\hline P16 & $0.42 \pm 0.14$ & $1.35 \pm 0.9$ & $3.9 \pm 0.87$ & $\begin{array}{c}0.004 \\
<0.001\end{array}$ & $<0.001$ \\
\hline
\end{tabular}


Table (3): Diagnostic accuracy of the different studied markers for HCC

\begin{tabular}{cccccccccc}
\hline & & \multicolumn{9}{c}{ 95\% CI } & Cutoff & Sensitivity & Specificity & Accuracy \\
- Variable & AUC & p & Lower & Upper & value & $(\%)$ & $(\%)$ & $(\%)$ \\
\hline APC1 & 0.907 & $<0.001$ & 0.816 & 0.997 & 2.39 & 100 & 84 & 92 \\
BMP4 & 0.953 & $<0.001$ & 0.00 & 1 & 2.65 & 100 & 94 & 97 \\
TSPYL5 & 0.869 & $<0.001$ & 0.766 & 0.972 & 3.78 & 100 & 77 & 88.5 \\
P16 & 0.989 & $<0.001$ & 0.00 & 1 & 2.25 & 100 & 90 & 95 \\
\hline
\end{tabular}

AUC: area under the curve, CI: Confidence interval.

Table (4): Diagnostic accuracy of the different studied markers for CLD

\begin{tabular}{|c|c|c|c|c|c|c|c|c|}
\hline \multirow[b]{2}{*}{ Variable } & \multirow[b]{2}{*}{ AUC } & \multicolumn{3}{|c|}{$95 \%$ CI } & \multirow[b]{2}{*}{$\begin{array}{c}\text { Cutoff } \\
\text { value }\end{array}$} & \multirow[b]{2}{*}{$\begin{array}{c}\text { Sensitivity } \\
(\%)\end{array}$} & \multirow[b]{2}{*}{$\begin{array}{c}\text { Specificity } \\
(\%)\end{array}$} & \multirow[b]{2}{*}{$\begin{array}{c}\text { Accuracy } \\
(\%)\end{array}$} \\
\hline & & $\begin{array}{c}\mathbf{p} \\
\text { value }\end{array}$ & $\begin{array}{l}\text { Lower } \\
\text { Bound }\end{array}$ & $\begin{array}{c}\text { Upper } \\
\text { Bound }\end{array}$ & & & & \\
\hline APC1 & 0.42 & 0.38 & 0.24 & 0.59 & 2.2 & 60 & 54 & 57 \\
\hline BMP4 & 0.34 & 0.034 & 0.14 & 0.46 & 1.22 & 60 & 24 & 42 \\
\hline TSPYL5 & 0.58 & 0.35 & 0.42 & 0.75 & 3 & 100 & 47 & 73.5 \\
\hline P16 & 0.4 & 0.31 & 0.24 & 0.57 & .72 & 66 & 50 & 58 \\
\hline
\end{tabular}

AUC: area under the curve, CI: Confidence interval.

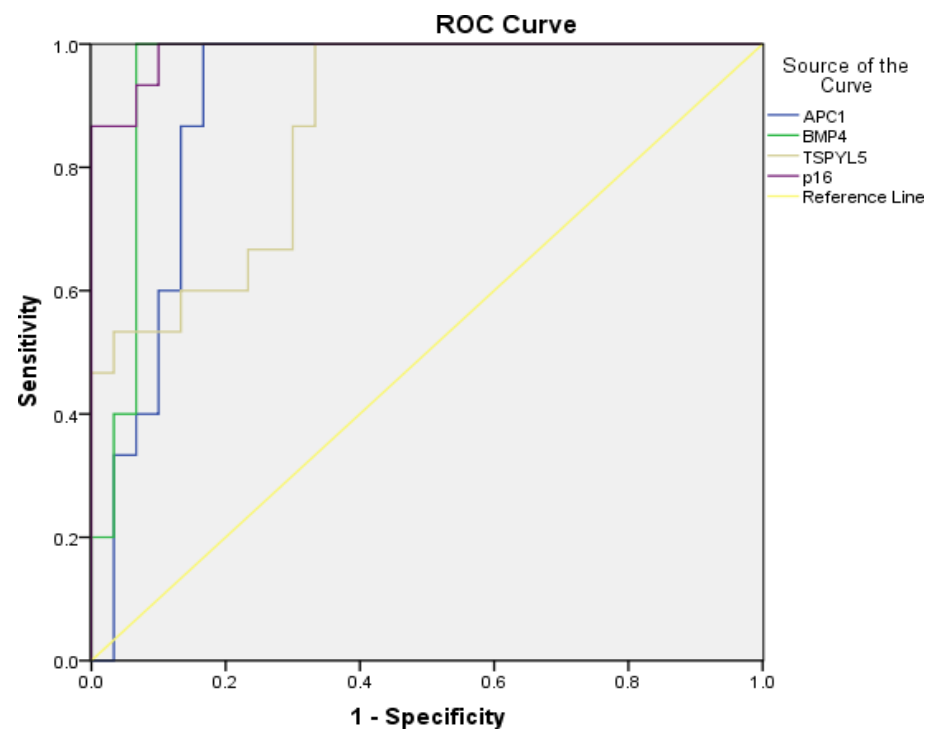

Fig. 1: ROC curve for (APC1, BMP4, TSPYL5 and P16) genes expression in HCC group. 


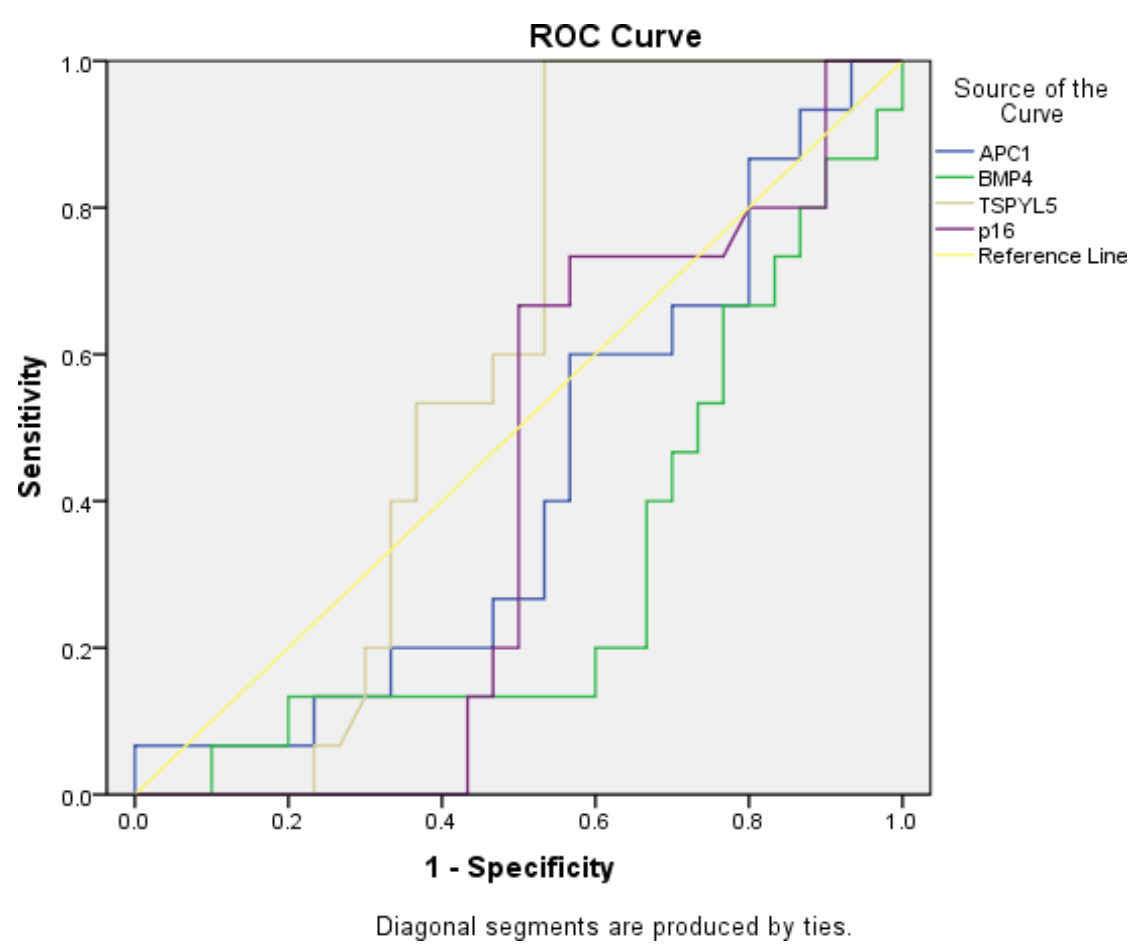

Fig. 2: ROC curve for (APC1, BMP4, TSPYL5 and P16) genes expression in CLD group.

\section{Discussion}

In Egypt, HCC is the second most common cancer in men and the 6 the most common cancer in women (8). A study reported that HCC present in $21 \%$ of Egyptian cirrhotic patients, due to different causes of cirrhosis, this rising incidence of HCC could be explained through improvements in all screening programs and diagnostic tools (9). In the current study, RT Taqman PCR approach was used to identify the role of blood level of ACP1, P16, BMP4 and TSPYL5 genes expression as promising biomarkers candidates for diagnosis of HCC patients. The mean age of patients with $\mathrm{HCC}$ was $55 \pm 4.7$ years (range 39-70 years) which was older than the chronic $\mathrm{HCV}$ and control groups but without significant difference among them ( $p>0.05$ ). This result agreed with A study that reported in another Egyptian study including $41 \mathrm{HCC}$ patients that, the mean

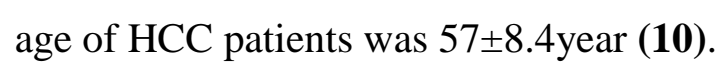

Concerning complete blood count in this study, hemoglobin level was lower in HCC group (mean $8.6 \mathrm{~g} / \mathrm{dl}$ ) compared with CLD group $($ mean $9.8 \mathrm{~g} / \mathrm{dl})$ with $(\mathrm{p} 1<0.001)$ and controls (mean14.6g/dl) with $(\mathrm{p} 2<0.001)$. This result was consistent with the study who reported that HCC is often characterized by mild anemia (11). 
According to the liver profile, the mean values of PT, s. bilirubin were significantly higher in HCC group than in the CLD group ( $\mathrm{p} 1=0.02)$, but serum albumin was significantly lower ( $1=0.6)$ in HCC group than in the CLD group. These results were consistent with the liver profile tests (albumin and prothrombin time) were more frequently abnormal in HCC than in chronic hepatitis and cirrhosis (12).

In current study, there was a significant increase in Acid phosphatase locus1 (APC1) gene methylation expression in HCC patients compared to the normal control $(\mathrm{p}<0.001)$.

A significant increase in APC1 gene expression in HCC patients compared to CLD patients $(\mathrm{p}=0.01)$ but no significant difference between CLD patients and normal control $(p=0.07)$. ROC curve for APC1 gene methylation expression for prediction of chronic liver disease wasn't significant but it was significant for prediction of HCC $(\mathrm{p}<0.001)$ and showed that the best - chosen cut-off level was (2.39) at which the sensitivity was $100 \%$ and the specificity was $84 \%$. The area under curve (AUC) was 0.907.

Similarly, on a study to detect the special methylation profile in peripheral blood for HCC. 55 HCCs and 54 CLDs were tested by methylation- specific PCR (MSP). In
$\mathrm{HCC}$, the methylation frequencies were $78.18 \%$ in APC while in CLD, the methylation frequencies were $27.78 \%$. The methylation frequencies of APC, was higher in HCC than in CLD $(\mathrm{P}<0.01)(\mathbf{1 3})$. A study, methylation levels of ACP1 was sig liver tissues $(\mathrm{p}<0.001)$. ROC curve for prediction of HCC, AUC was $0.753(95 \%$ CI: $0.700-0.806), \mathrm{p}<0.001$ (7).

In contrast a significant difference in the methylation frequency of APC between $\mathrm{CH}$ and HCC cases where APC was more frequent in the $\mathrm{CH}$ group was observed (14).

The current study shows a significant increase in BMP4 gene methylation expression in $\mathrm{HCC}$ patients compared to the normal control $(\mathrm{p}<0.001)$. Significant increase in BMP4 gene methylation expression in $\mathrm{HCC}$ patients compared to CLD patients $(\mathrm{p}<0.001)$. No significant difference between CLD patients and normal control $(\mathrm{p}=0.89)$. ROC curve for BMP4 gene methylation expression for prediction of chronic liver disease wasn't significant but was significant for prediction of HCC $(\mathrm{p}<0.001)$ and showed the best -chosen cut-off level (2.65), at which the sensitivity was $100 \%$ and the specificity was $94 \%$. The area under curve (AUC) was 0.953.

Increased BMP4 protein expression by immune-histochemistry in 120/156 (77\%) 
HCC tissues compared to $19 / 156$ (12\%) adjacent non-tumor tissues. Chiu et al. (16) reported increased BMP4 mRNA expression by real-time PCR in $60 \%$ of 71 paired HCC tissues was described (15).

A study for methylation levels of BMP4 which was significantly increased in HCC tissues compared with adjacent non-tumor tissues and normal liver tissues $(\mathrm{p}<0.0001)$. Moreover, BMP4 methylation was remarkably higher in adjacent non-tumor tissues than normal liver tissues $(\mathrm{p}=0.016)$. ROC curve for prediction of HCC, AUC was 0.785 (95\% CI: $0.733-0.837)$, $\mathrm{p}<0.001$ (7).

In this study, there was a significant increase in TSPYL5 gene methylation expression in CLD and HCC patients compared to the normal control $(\mathrm{p}<0.001)$. Significant increase in TSPYL5 gene expression in HCC patients compared to CLD patients $(p=0.003)$. ROC curve for TSPYL5 gene methylation expression for prediction of CLD wasn't significant but was significant for HCC prediction $(\mathrm{p}<0.001)$ and showed the best -chosen cut-off level (3.78), at which the sensitivity was $100 \%$ and the specificity was $77 \%$. AUC was 0.869 .

The gene methylation of TSPYL5 was higher in tumor tissue than non- tumor tissue (71\% vs 45\%) (17). The found methylation level of TSPYL5 was significantly increased in HCC tissues compared with adjacent non-tumor tissues and normal liver tissues $(\mathrm{p}<0.0001)$. Moreover, TSPYL5 gene methylation was remarkably higher in adjacent non-tumor tissues than normal liver tissues $(\mathrm{p}<0.001)$. ROC curve for prediction of HCC, AUC was 0.917 (95\% CI: $0.886-0.948)$, $\mathrm{p}<0.001$ (7).

In this study, there was a significant increase in p16 gene methylation expression in CLD and HCC patients compared to the normal control $(\mathrm{p}=0.004)$ and a significant increase in p16 gene methylation expression in HCC patients compared to CLD patients ( $\mathrm{p}<0.001)$. ROC curve for P16 gene methylation expression for prediction of CLD wasn't significant but was significant for prediction of HCC $(\mathrm{p}<0.001)$ and showed the best -chosen cut-off level was (2.25), at which the sensitivity was $100 \%$ and the specificity was $90 \%$. AUC was 0.989 .

P16 is one of the most reported genes that was shown to be hyper methylated and associated with clinical parameters in HCC. It is a tumor suppressor gene that plays a role in cell cycle regulation. It was methylated in many other cancers as well. They showed that methylation of p16 gene increased from cirrhotic tissue to HCC. Studies have also shown that hepatitis virus positive HCC samples have higher p16 
methylation compared to $\mathrm{HCC}$ with no viral infection (18-20).

In a meta-analysis, HCC was compared to chronic hepatitis including 525 HCC patients and 252 patients with chronic hepatitis, the results of tissue samples showed that the frequency of $\mathrm{p} 16$ promoter methylation in HCC was significantly higher than in chronic hepatitis $(\mathrm{P}<0.001)$ (12).

A recent study performed to examine the regularity and role of p16 methylation in HCC blood. The risk of HCC's histological process was investigated using both Metaanalysis and the quantitative correlation analysis. p16 methylation frequencies in blood were gradually increased from $0 \%$ in normal to $10 \%$ in benign disease, to $60 \%$ in HCC development (10).

In patients with $\mathrm{HCC}$, there was a positive correlation between the gene expression and there was a negative correlation between each of (APC1, BMP4, TSPYL5 and $\mathrm{P} 16)$ with ( $\mathrm{Hb}$ concentration, platelets count and serum albumin) $r=<0.3$ while there was a positive correlation between each of the man $d$ (INR, total Bilirubin, alfa feto-protein, ALT and AST)

$r=<0.01$.

In contrast, No correlation was found between BMP4 expression and tumor grading and size, patient's age or gender, serum levels of transaminases or Bilirubin, and the etiology of the underlying liver disease (13).

This study had some limitations; firstly, lack of taking liver biopsy so we could not histopathologically assist hepatic focal lesion \& its nearby tissue (25). Secondly, we did not examine the methylation of the carcinoid and HCC tissues, which will assist in stating that the alteration of methylation occurs early or late in the hepatocarcino-genesis. Thirdly, this was across-sectional study so we couldn't follow up the patients to assess the outcome and its correlation with gene methylation and finally, the small sample size didn't allow for better analytic features of these biomarkers.

\section{Conclusions:}

Hyper methylation of p16, ACP1, BMP4, and TSPYL5 are common events in patients with HCC and could be used as potentially detectable biomarkers in HCC.). The diagnostic accuracy of the different studied markers for HCC was 92\%, 97\%, $88.5 \%$ \& $95 \%$ in the 4 studied biomarkers respectively.

\section{References}

1. Abdel-Atti E. HCC Burden in Egypt. Gastroenterol Hepatol Open Access. 2015; 2(3):14-5.

2. Atta MM, el-Masry SA, Abdel-Hameed M, Baiomy HA, Ramadan NE. Value of serum anti- 
p53 antibodies as a prognostic factor in Egyptian patients with hepatocellular carcinoma. Clin Biochem (Internet). 2008 Oct; 41(14-15):11311139. Available from: https://doi.org/10.1016/j.clinbiochem.2008.06.006

3. Chiu C-Y, Kuo K-K, Kuo T-L, Lee K-T, Cheng K-H. The Activation of MEK/ERK Signaling Pathway by Bone Morphogenetic Protein 4 to Increase Hepatocellular Carcinoma Cell Proliferation and Migration. Mol Cancer Res. 2012 Feb 21; 10:415-27.

4. El-Mougy FA, Youssef MM, Omran DA, Sharaf SA, El-Sayed HH, Rabie WA, et al. Aberrant p16INK4A methylation: Relation to viral related chronic liver disease and hepatocellular carcinoma. South Asian J cancer. 2014 Jan; 3(1):1-4.

5. El-Zayadi A-R, Badran HM, Barakat EMF, Attia M el-D, Shawky S, Mohamed MK, et al. Hepatocellular carcinoma in Egypt: a single center study over a decade. World J Gastroenterol. 2005 Sep;11(33):5193-8.

6. Feng Q, Stern JE, Hawes SE, Lu H, Jiang M, Kiviat NB. DNA methylation changes in normal liver tissues and hepatocellular carcinoma with different viral infection. Exp Mol Pathol (Internet). 2010 Apr; 88(2):287-292. Available from: https:// europepmc. org/articles/PMC2848881.

7. Ferrín G, Aguilar-Melero P, Rodríguez-Perálvarez M, Montero-Álvarez JL, de la Mata M. Biomarkers for hepatocellular carcinoma: diagnostic and therapeutic utility. Hepat Med (Internet). 2015 Apr 13; 7:1-10. Available from: https://pubmed.ncbi.nlm.nih.gov/25926760.

8. Guo X, Xiong L, Zou L, Zhao J. Upregulation of bone morphogenetic protein 4 is associated with poor prognosis in patients with hepatocellular carcinoma. Pathol Oncol Res (Internet). 2012
Jul;18(3):635-640.Available from:

https://doi.org/10.1007/s12253-011-9488-2.

9. Hsu C-Y, Lee Y-H, Hsia C-Y, Huang Y-H, Su C$\mathrm{W}$, Lin $\mathrm{H}-\mathrm{C}$, et al. Performance status in patients with hepatocellular carcinoma: determinants, prognostic impact, and ability to improve the Barcelona Clinic Liver Cancer system. Hepatology. 2013 Jan; 57(1):112-9.

10. Jiang C-G, Chen Q, Wu L, Wang G, Ma J. The innovative regularity and role of p16 methylation in blood during HCC development. J Cancer. 2018 Apr 27; 9:1925-31.

11. Katoh H, Shibata T, Kokubu A, Ojima H, Fukayama M, Kanai Y, et al. Epigenetic instability and chromosomal instability in hepatocellular carcinoma. Am J Pathol (Internet). 2006 Apr; 168(4):1375-84. Available from: https://pubmed.ncbi.nlm.nih.gov/16565510.

12. Lv X, Ye G, Zhang X, Huang T. p16 Methylation was associated with the development, age, hepatic viruses infection of hepatocellular carcinoma, and p16 expression had a poor survival: A systematic meta-analysis (PRISMA). Medicine (Baltimore). 2017 Sep; 96(38):e8106.

13. Maegdefrau U, Amann T, Winklmeier A, Braig S, Schubert T, Weiss TS, et al. Bone morphogenetic protein 4 is induced in hepatocellular carcinoma by hypoxia and promotes tumour progression. J Pathol. 2009 Aug; 218(4):520-9.

14. Mah W-C, Lee CGL. DNA methylation: potential biomarker in Hepatocellular Carcinoma. Biomark Res (Internet). 2014;2(1):5. Available from: https://doi.org/10.1186/2050-7771-2-5.

15. Malaguarnera $M$, Bentivegna $P$, Di Fazio I, Laurino A, Romano M, Trovato BA. (Erythropoietin in hepatocellular carcinoma). Bull Cancer. 1996 Dec; 83(12):977-80.

16. Mikeska T, Craig JM. DNA methylation biomarkers: cancer and beyond. Genes (Basel) 
(Internet). 2014 Sep 16; 5(3):821-64. Available from: https://pubmed.ncbi.nlm.nih.gov/25229548.

17. Ofosu A, Gurakar A. Current Concepts in Hepatocellular Carcinoma and Liver Transplantation: A Review and 2014 Update. Euroasian $\mathbf{J}$ hepato-gastroenterology (Internet). 2015/01/06. 2015;5(1):19-25. Available from: https://pubmed.ncbi.nlm.nih.gov/29201680.

18. Omar A, Abou-Alfa GK, Khairy A, Omar H. Risk factors for developing hepatocellular carcinoma in Egypt. Chinese Clin Oncol. 2013 Dec; 2(4):43.

19. Qiu X, Hu B, Huang Y, Deng Y, Wang X, Zheng F. Hypermethylation of ACP1, BMP4, and TSPYL5 in Hepatocellular Carcinoma and Their Potential Clinical Significance. Dig Dis Sci. 2016 Jan; 61(1):149-57.

20. Shen J, Wang S, Zhang Y-J, Kappil M, Wu H-C, Kibriya MG, et al. Genome-wide DNA methylation profiles in hepatocellular carcinoma. Hepatology. 2012 Jun;55(6):1799-808.

21. WHO. IARC launches the definitive cancer statistics resource GLOBOCAN 2008. World Health. 2010; (June):1-2.
22. Wu H-C, Shen J, Yang H-I, Tsai W-Y, Chen C-J, Santella RM. Blood DNA methylation markers in prospectively identified hepatocellular carcinoma cases and controls from Taiwan. World J Hepatol. 2016 Feb; 8(5):301-6.

23. Zekri A-RN, Bahnasy AA, Shoeab FEM, Mohamed WS, El-Dahshan DH, Ali FT, et al. Methylation of multiple genes in hepatitis $\mathrm{C}$ virus associated hepatocellular carcinoma. J Adv Res (Internet). 2013/01/26. 2014 Jan; 5(1):27-40. Available from: https://pubmed.ncbi.nlm.nih.gov/25685469.

24. Zhang C, Li J, Huang T, Duan S, Dai D, Jiang D, et al. Meta-analysis of DNA methylation biomarkers in hepatocellular carcinoma. Oncotarget. 2016 Dec; 7(49):81255-67.

25. Zhang Y, Yang B, Wang Y, Gao Y, Bai T, Bai Y, et al. Methylation profile of tumor suppressor genes in the cell-free DNA of plasma in hepatocellular carcinoma. Chinese J Clin Oncol. 2013 Dec 15; 40:1436-40.

To cite this article : Dalia M. Abd El-Hassib, Azza A. Abo senna, Ebada M. Said, Wafaa M. Abdallah, Nermien H. Ibrahiem, Seham Gouda. Molecular Assessment of DNA Methylation Biomarkers in Egyptian Hepatocellular carcinoma Patients. BMFJ 2021;38(3):925-936. DOI: 10.21608/bmfj.2021.67156.1395 

Benha medical journal, vol. 38, issue 3, 2021 